\title{
In vitro and in vivo studies on gelatin-siloxane nanoparticles conjugated with SynB peptide to increase drug delivery to the brain
}

This article was published in the following Dove Press journal:

International Journal of Nanomedicine

2I February 2012

Number of times this article has been viewed

\author{
Xin-hua Tian' \\ Feng Wei' \\ Tian-xiao Wang ${ }^{2}$ \\ Peng Wang' \\ Xiao-ning Lin' \\ Jun Wang ${ }^{2}$ \\ Dong Wang ${ }^{2}$ \\ Lei $\operatorname{Ren}^{2,3}$
}

'Neurosurgical Department of Affiliated Zhongshan Hospital, ${ }^{2}$ Research Center of Biomedical Engineering, Department of Biomaterials, College of Materials, ${ }^{3}$ State Key Laboratory for Physical Chemistry of Solid Surfaces, Xiamen University, Xiamen, People's Republic of China
Correspondence: Feng Wei Neurosurgical Department of Affiliated Zhongshan Hospital, Xiamen University, 209 South Hubin Road, Xiamen 361004, People's Republic of China Tel +86 5922292352

Fax +86 5922212328

Email weif0I0@hotmail.com
Background: Nanobiotechnology can provide more efficient tools for diagnosis, targeted and personalized therapy, and increase the chances of brain tumor treatment being successful. Use of nanoparticles is a promising strategy for overcoming the blood-brain barrier and delivering drugs to the brain. Gelatin-siloxane (GS) nanoparticles modified with Tat peptide can enhance plasmid DNA transfection efficiency compared with a commercial reagent.

Methods: SynB-PEG-GS nanoparticles are membrane-penetrable, and can cross the bloodbrain barrier and deliver a drug to its target site in the brain. The efficiency of delivery was investigated in vivo and in vitro using brain capillary endothelial cells, a cocultured blood-brain barrier model, and a normal mouse model.

Results: Our study demonstrated that both SynB-PEG-GS and PEG-GS nanoparticles had a spherical shape and an average diameter of 150-200 nm. It was shown by MTT assay that SynB-PEG-GS nanoparticles had good biocompatibility with brain capillary endothelial cells. Cellular uptake by SynB-PEG-GS nanoparticles was higher than that for PEG-GS nanoparticles for all incubation periods. The amount of SynB-PEG-GS nanoparticles crossing the cocultured blood-brain barrier model was significantly higher than that of PEG-GS nanoparticles at all time points measured $(P<0.05)$. In animal testing, SynB-PEG-GS nanoparticle levels in the brain were significantly higher than those of PEG-GS nanoparticles at all time points measured $(P<0.01)$. In contrast with localization in the brain, PEG-GS nanoparticle levels were significantly higher than those of SynB-PEG-GS nanoparticles $(P<0.01)$ in the liver.

Conclusion: This study indicates that SynB-PEG-GS nanoparticles have favorable properties with regard to morphology, size distribution, and toxicity. Moreover, the SynB-PEG-GS nanoparticles exhibited more efficient brain capillary endothelial cell uptake and improved crossing of the blood-brain barrier. Further, biodistribution studies of rhodamine-loaded nanoparticles demonstrated that modification with the SynB peptide could not only improve the ability of PEG-GS nanoparticles to evade capture in the reticuloendothelial system but also enhance their efficiency in crossing the blood-brain barrier.

Keywords: nanoparticles, peptide, blood-brain barrier, brain targeting delivery

\section{Introduction}

The blood-brain barrier is a complex physiological checkpoint in the central nervous system that inhibits free diffusion of circulating molecules from the blood into the brain. Many brain diseases cannot be treated due to the presence of barriers in the brain. Therefore, development of a novel drug delivery system which would significantly enhance the delivery of therapeutic agents across the blood-brain barrier holds the key to treatment of a number of brain diseases and is an impending mission for research workers. 
In recent years, various strategies have been proposed to circumvent the blood-brain barrier. Nanobiotechnology will provide more efficient tools for diagnosis, targeted personalized therapy, and increase the chances of curative treatment for brain tumors. ${ }^{1}$ The use of nanoparticles represents a promising strategy for overcoming the blood-brain barrier. ${ }^{2}$ Nanoparticle systems are increasingly demonstrating an advantage in effective transportation of various drugs, including temozolomide, ${ }^{3}$ loperamide, ${ }^{4}$ and doxorubicin, ${ }^{5}$ which are not normally able to penetrate the blood-brain barrier. Further, due to their small size and appropriate surface functionalization, nanoparticles can flow easily through blood capillaries and enter target cancer cells. ${ }^{6,7}$

Using appropriate surface modification, nanoparticle carriers have been shown to have good cellular uptake and low cytotoxicity in vitro and in vivo. Methods for surface modification of nanoparticles have been developed and include decoration with poly(ethylene glycol) (PEG), ${ }^{8,9}$ polysorbate- $80,{ }^{3}$ monoclonal antibody, and cationic cellpenetrating peptides. ${ }^{10}$ Recently, nanoparticles with multiple modifications for delivery in the central nervous system have been constructed by a number of research groups. These include lactoferrin-conjugated polyethylene glycolpolylactide-polyglycolide (PEG-PLGA) nanoparticles ${ }^{11}$ and a leptin-derived 30 amino acid peptide-modified pegylated poly-L-lysine dendrigraft. ${ }^{12}$

Nanoparticles coated with PEG show potential for use as potent drug carriers because they are able to evade the reticuloendothelial system and circulate in the blood for a long period of time. ${ }^{13,14}$ Gao et $\mathrm{al}^{15}$ and $\mathrm{Lu}$ et $\mathrm{al}^{16}$ reported a poly(lactic acid) nanoparticle system via PEG and targeted molecular modification. They demonstrated increased uptake of these nanoparticles by brain capillary endothelial cells. In an in vivo experiment, there was higher localized nanoparticle accumulation in the brain and a 2.98-fold increase in the area under the concentration-time curve over 24 hours compared with controls not exposed to the modified nanoparticles.

Cationic cell-penetrating peptide-mediated endocytosis is one of the mechanisms by which drug carriers cross the blood-brain barrier. Cell-penetrating peptides are a group of short peptides with a potent ability to penetrate the blood-brain barrier, and have been investigated extensively in recent decades and found to be materials well suited for development as drug delivery vehicles. The advantages of peptides include their relatively small molecular weight, ease of synthesis, relatively low cytotoxicity and immunogenicity, and degradation in vivo to naturally occurring compounds. ${ }^{17,18}$ The SynB peptides (RGGRLSYSRRRFSTSTGR) are a family of cell-penetrating peptides that show charge-mediated blood-brain barrier selectivity occurring via a caveolaeindependent pathway. ${ }^{19}$ Furthermore, intracellular delivery of SynB peptides has been used extensively in cationic cell-penetrating peptide vector-mediated strategies which enable passage of a large variety of small molecules as well as proteins across cell membranes in vitro and across the blood-brain barrier in vivo. ${ }^{20,21}$

The aim of our study was to confirm whether SynBPEG nanoparticles decorated with gelatin-siloxane (SynBPEG-GS) could traverse the blood-brain barrier from the systemic circulation and increase the dose of drug reaching the brain in vivo and in vitro. In this study, a micellar brain delivery system was constructed by conjugating SynB-PEG with gelatin-siloxane nanoparticles. Its properties, including structure, morphology, and size distribution, were evaluated. Further, the toxicity of SynB-PEG-GS nanoparticles was assessed by MTT assay using brain capillary endothelial cells. In addition, the efficiency of transport of SynBPEG-GS nanoparticles across brain capillary endothelial cells was investigated in vivo and in vitro, using a coculture blood-brain barrier model and a normal mouse model, respectively.

\section{Materials and methods Materials and animals}

Gelatin (bloom number 240-270, pH 4.5-5.5) was purchased from BBI (Madison, WI). 3-Glycidoxypropyl-trimethoxysilane (GPSM) and 3-aminopropyl-trimethoxysilane (APTMS) were purchased from Acros Organics (Fair Lawn, NJ). N-succinimidyl-3-(2-pyridyldithio) propionate (SPDP) was purchased from Pierce Biotechnology Inc (Rockford, IL). 1-[3-(dimethylamino) propyl]-3-ethylcarbodiimide (EDC) and N-Hydroxysuccinimide (NHS) were provided by Chinese GL Biochem Ltd, (Shanghai, China). $\mathrm{NH}_{2}$-PEG-COOH was provided by Chinese Beijing Kaizheng Biotech Development Co, (Beijing, China). N-pys-activated C-terminal Cys containing SynB peptide (RGGRLSYSRRRFSTSTGR) and rhodamine (TAMRA)-labeled SynB peptide were provided by Chinese Peptide Co, (Hangzhou, China). All materials used were of analytical grade and used without further purification.

Adult nude mice (6 weeks old, 18-20 g, on a Balb/c $\mathrm{nu} / \mathrm{nu}$ background) and Sprague-Dawley rats (3 weeks old) were obtained from the laboratory animal center of Xiamen University. The animals used for the experiment were treated according to the protocols evaluated and approved by the Chinese National Science and Technology Committee guidelines. 


\section{Preparation of nanoparticles}

Amino-functionalized gelatin-siloxane nanoparticles were prepared according to previously reported methods. ${ }^{22}$ Briefly, $0.2 \mathrm{~g}$ of GPSM was added to $1 \%$ gelatin solution in $\mathrm{HCl}\left(\mathrm{pH} \mathrm{3.0)}\right.$ at $40^{\circ} \mathrm{C}$ under stirring for 20 minutes, and the mixture was then continuously stirred for another 30 minutes at $60^{\circ} \mathrm{C}$. Generation of gelatin-siloxane nanoparticles was associated with the introduction of APTMS into the above mixture. The resulting gelatin-siloxane nanoparticles were purified by centrifugation $\left(14,000 \mathrm{rpm}, 25^{\circ} \mathrm{C}, 20\right.$ minutes $)$ three times. We conjugated rhodamine $\mathrm{B}$ isothiocyanate dye (RITC) to the surfaces of gelatin-siloxane nanoparticles using the reaction between the isothiocyanate group of RITC and the primary amino group of gelatin-siloxane nanoparticles. Then, $0.3 \mathrm{mg}$ of RITC was added to $50 \mathrm{mg}$ of gelatin-siloxane nanoparticles in $\mathrm{pH} 8.0$ phosphate-buffered solution and incubated in a rotator for 2 hours at room temperature. After purification by centrifugation, PEG was linked to the gelatinsiloxane nanoparticle surfaces using EDC and NHS as coupling reagents. The sulfhydryl group was then introduced to the surface of PEGylated gelatin-siloxane nanoparticles via SPDP. SynB peptide with a free sulfhydryl group at the end of the strand was subsequently coupled to the nanoparticles via a disulfide bond. SynB-PEG-GS nanoparticles were finally obtained by centrifugation for 20 minutes at $25^{\circ} \mathrm{C}$ and $19,000 \mathrm{rpm}$, and washed three times with deionized water.

\section{Cell cultures}

Primary cultures of rat brain capillary endothelial cells were obtained from 3-week-old Sprague-Dawley rats, as previously described ${ }^{23}$ First, gray matter isolated from rat brain was put into a glass homogenizer for homogenizing, then passed through a cell filter $(150 \mu \mathrm{m}, 75 \mu \mathrm{m})$ and digested with collagenase type $2(1 \mathrm{mg} / \mathrm{mL})$ in a shaker for one hour at $37^{\circ} \mathrm{C}$. The cell suspension was separated by centrifugation in $20 \%$ bovine serum albumin-endothelial cell medium $(1000 \times \mathrm{g}$ for 20 minutes). Next, the brain capillary endothelial cells were collected and washed twice in endothelial cell medium before plating on $35 \mathrm{~mm}$ plastic dishes coated with collagen type IV $0.1 \mathrm{mg} / \mathrm{mL}$ (ScienCell, Carlsbad, CA). Brain capillary endothelial cell cultures were maintained in endothelial cell medium supplemented with $1 \%$ endothelial cell growth supplement (ScienCell), 5\% fetal bovine serum (ScienCell), and 1\% penicillin/streptomycin (ScienCell) at $37^{\circ} \mathrm{C}$ in a humidified atmosphere of $5 \% \mathrm{CO}_{2} / 95 \% \mathrm{O}_{2}$. On the third day, the old medium were replaced in the cell culture dishes. When the cell cultures reached $80 \%$ confluence, the purified endothelial cells were digested with trypsin solution
$(0.125 \%, \mathrm{w} / \mathrm{v})$, checked by immunostaining for endothelial cell factor VIII (Beijing Biosynthesis Biotechnology Co, Ltd, China), and used to construct in vitro blood-brain barrier models.

Cerebral astrocytes were obtained from neonatal SpragueDawley rats. Cortical brain tissue pieces were removed from the brain and mechanically dissociated in astrocyte culture medium (Dulbecco's Modified Eagle's Medium supplemented with $10 \%$ fetal bovine serum, $10 \%$ calf serum, and $1 \%$ penicillin/streptomycin). Cells were seeded into cell culture flasks at $37^{\circ} \mathrm{C}$ with a humidified atmosphere of 5\% $\mathrm{CO}_{2} / 95 \% \mathrm{O}_{2}$. When cultures reached approximately $80 \%$ confluence, flasks with confluent cultures were shaken at $37^{\circ} \mathrm{C}$ ( $200 \mathrm{rpm}, 12$ hours) in order to obtain type 1 astrocytes. The purity of the astrocytes was checked by immunostaining for glial fibrillary acidic protein (Beijing Biosynthesis Biotechnology $\mathrm{Co}, \mathrm{Ltd}$,), and the cells were used for constructing in vitro blood-brain barrier models.

\section{Construction of cocultured blood-brain barrier models}

Astrocytes $\left(1.5 \times 10^{5}\right.$ cells $\left./ \mathrm{mL}\right)$ were seeded on the bottom side of the polyester membrane of a Transwell insert (Corning, New York, NY), and the Transwell insert was placed in 6-well culture plates in the opposite direction of bottom-top. After culture for 24 hours, endothelial cells $\left(1.6 \times 10^{5}\right.$ cells $\left./ \mathrm{mL}\right)$ were seeded on the inside of the Transwell insert, and the Transwell insert was placed in 12-well culture plates. These cells were cultured in endothelial cell medium (ScienCell) supplemented with $1 \%$ endothelial cell growth supplement (ScienCell), 5\% fetal bovine serum (ScienCell), and $1 \%$ penicillin/streptomycin (ScienCell) at $37^{\circ} \mathrm{C}$ and $5 \%$ $\mathrm{CO}_{2} / 95 \% \mathrm{O}_{2}$ saturated humidity. The endothelial cell medium was changed every 3 days. The cocultured cells were grown for 14 days to confluence before experiment.

\section{Immunofluorescent staining}

In order to determine the brain endothelial tight junction proteins for various blood-brain barrier models, a cocultured blood-brain barrier model was stained with claudin- 5 . The in vitro blood-brain barrier model was washed with phosphatebuffered solution and fixed with $4 \%$ polyphosphate formaldehyde solution for 20 minutes at room temperature. The blood-brain barrier model was then blocked with $10 \%$ rabbit serum for 30 minutes and incubated with rabbit anticlaudin- 5 (1:50, Santa Cruz) for 2 hours at $37^{\circ} \mathrm{C}$. Next, these samples were incubated with TRITC-labeled antirabbit IgG (Beijing CoWin Bioscience Co, Ltd, Beijing, China) for one hour 
at $37^{\circ} \mathrm{C}$. For nuclear staining, the cells were incubated with 4.6-diamidino-2-phenylindole (DAPI, 1:500; Roche, Basel, Switzerland) for 15 minutes at room temperature. Finally, the blood-brain barrier model was washed three times with phosphate-buffered solution and sealed pieces were examined by confocal laser scanning microscopy (FV 1000, Olympus, Shinjuku-ku, Japan).

\section{Characterization of nanoparticles}

Observation of gelatin-siloxane, PEG-GS, and SynB-PEG-GS nanoparticles was carried out using transmission electron microscopy (2100 HC, Japan) at an operating voltage of $200 \mathrm{kV}$ in bright-field mode. Dilute suspensions of nanoparticles in water were dropped onto a copper grid and then air-dried for analysis by transmission electron microscopy. The mean diameter and zeta potential of the nanoparticles were measured using a Nano-ZS zetasizer dynamic light scattering detector (Malvern Instruments, Worcestershire, UK). Each experiment was conducted 22 times for reproducibility.

\section{MTT assay}

Brain capillary endothelial cells were cultured in endothelial cell medium supplemented with $5 \%$ fetal bovine serum, $1 \%$ endothelial cell growth supplement, and 1\% penicillin/streptomycin at $37^{\circ} \mathrm{C}$, with $5 \% \mathrm{CO}_{2} / 95 \% \mathrm{O}_{2}$ saturated humidity. Brain capillary endothelial cells were seeded into 96-well plates at a density of $5 \times 10^{3}$ cells/well and incubated at $37^{\circ} \mathrm{C}$ with $5 \% \mathrm{CO}_{2}$ for 24 hours to allow cell attachment. PEG-GS and SynB-PEG-GS nanoparticles were diluted with $100 \mu \mathrm{L}$ of serum-free endothelial cell medium to different concentrations $(100-600 \mu \mathrm{g} / \mathrm{mL})$ and incubated with brain capillary endothelial cells, with cells not exposed to nanoparticles serving as controls. After 4 and 12 hours of coincubation, the medium was removed and the cells were washed with phosphate-buffered solution. The fresh complete culture medium containing $20 \mu \mathrm{L}$ of MTT solution ( $5 \mathrm{mg} / \mathrm{mL}$ in phosphate-buffered solution) was cultured for a further 4 hours. The MTT solution was removed and $100 \mu \mathrm{L}$ of dimethylsulfoxide was added (at $37^{\circ} \mathrm{C}$ for 30 minutes) to dissolve the formazan crystals that had formed. Cell viability was evaluated at $570 \mathrm{~nm}$ in a spectrophotometric microplate reader (Bio-tek ELX800, Winooski, VT). Each experiment was repeated five times, and the relative cell viability (\%) was expressed as a percentage in comparison with control cells.

\section{Cellular uptake of nanoparticles}

For the study of nanoparticle uptake by brain capillary endothelial cells, PEG-GS and SynB-PEG-GS nanoparticles were incubated with confluent monolayers of brain capillary endothelial cells (100 $\mu \mathrm{g}$ nanoparticles $/ 10^{5}$ cells/well) in serum-free endothelial cell medium at $37^{\circ} \mathrm{C}$ for different time periods (2, 4, and 6 hours). After incubation, the cells were collected, centrifuged, and resuspended in $300 \mu \mathrm{L}$ of $70 \%$ nitric acid and incubated at $200^{\circ} \mathrm{C}$ for 15 minutes, after which the cells were diluted $100 \times$ in distilled water for assay by inductively coupled plasma mass spectrometry. All samples were run in quadruplicate and the data show the average of four measurements.

\section{Model of nanoparticle transport across blood-brain barrier}

When the in vitro blood-brain barrier model was constructed, cells were grown for 14 days to confluence. On the day of the experiment, the cells were rinsed twice with serum-free endothelial cell medium. The medium was then added into the apical chamber at a concentration of $100 \mu \mathrm{g} / \mathrm{mL}$ for PEG-GS and SynB-PEG-GS nanoparticles. In the control wells, the same medium was added but without nanoparticles. A $1 \mathrm{~mL}$ volume of sample medium was taken from the basolateral compartment at 5, 10, 20, 40, and 80 minutes, and detected by inductively coupled plasma mass spectrometry. All samples were run five times and the data show the average of five measurements.

\section{Animal testing}

For the animal experiments, a total of 21 congenitally athymic nude male mice (6 weeks old, body weight 18-20 g, on Balb/c nu/nu background, laboratory animal center of Xiamen University, China) were randomly divided into three groups of seven mice each. Rhodamine-loaded PEG-GS nanoparticles and SynB-PEG-GS nanoparticles were prepared using physiological saline solution. The nanoparticle formulations were injected into the tail veins of nude mice ( $1 \mathrm{~mL}, 60 \mathrm{mg} / \mathrm{kg}$ ). At $0.5,1,2$, and 4 hours following injection, the mice were anesthetized using 10\% chloral hydrate $(0.6 \mathrm{~mL} / \mathrm{kg})$ and images were taken using the Maestro in vivo imaging system (CRI Inc, Hopkinton, MA). In order to analyze the quantitative distribution of the nanoparticles in vivo, the mice were sacrificed at $0.5,2,4,6,12$, and 24 hours after injection. The brains and livers were collected immediately, washed twice with physiological saline solution, and also visualized using the Maestro in vivo imaging system. The fluorescence signal intensity was quantified as the sum of all detected photon counts per second within the region of interest after subtracting the background luminescence and presented as total signal counts/scaled/second. 


\section{Statistical analysis}

All statistical analyses were performed using SPSS 13.0 (SPSS Inc, Chicago, IL). Data were reported as the mean \pm standard deviation. Student's $t$-test was used for comparisons between the treatment groups and control group. $P$ values $<0.05$ were considered to be statistically significant.

\section{Results}

\section{Characterization of nanoparticles}

The theoretical structure of the SynB-PEG-GS nanoparticles is shown in Figure 1. Gelatin-siloxane nanoparticles were prepared using GPSM and gelatin solution. Rhodamine B isothiocyanate dye was conjugated to the gelatin-siloxane nanoparticles via its primary amino group. $\mathrm{NH}_{2}$-PEG-COOH was linked to the gelatin-siloxane nanoparticle surfaces using EDC and NHS as coupling reagents. SPDP was used to conjugate PEG via NHS. Finally, sulfhydryl-containing SynB peptide (RGGRLSYSRRRFSTSTGR) was attached to this linker via a disulfide bond, which was from the SynB-PEG-GS nanoparticles.

Transmission electron microscopy showed that the SynBPEG-GS and PEG-GS nanoparticles were both spherical, and the average size of the various types of nanoparticles was 150-200 nm (Figure 2). Dynamic light scattering analysis was used to measure the size of the gelatin-siloxane, PEG-GS, and SynB-PEG-GS nanoparticles (Table 1). The particle sizes of gelatin-siloxane, PEG-GS, and SynB-PEG-GS nanoparticles were $180.73 \pm 11.57 \mathrm{~nm}, 182.91 \pm 10.30 \mathrm{~nm}$, and $194.55 \pm 6.43 \mathrm{~nm}$, respectively. Zeta potential measurement showed the charge values of gelatin-siloxane, PEG-GS, and SynB-PEG-GS nanoparticles to be $28.50 \pm 3.33 \mathrm{mV}$, $2.50 \pm 1.97 \mathrm{mV}$, and $31.82 \pm 3.11 \mathrm{mV}$, respectively.

\section{Immunofluorescent staining}

Brain capillary endothelial cells and astrocytes were isolated from the rat brain and grown in nonoverlapping continuous monolayers, and demonstrated to have an elongated, fusiform morphology and positive immunostaining for endothelial cell factor VIII (Figure 3A). The astrocytes were polygonal with long podocytic cell processes and immunostained positive for glial fibrillary acidic protein (Figure 3B). Immunostaining with claudin-5 was performed using the blood-brain barrier model of brain capillary endothelial cells and astrocytes cocultured under previously described conditions after 17 days (Figure 3C). High staining of claudin-5 was observed in the samples, and tight junction proteins in the blood-brain barrier model were strongly expressed in the vicinity of the cell borders.

\section{MTT assay}

The result of the MTT viability assay is shown in Figure 4. The viability of brain capillary endothelial cells treated with SynB-PEG-GS nanoparticles $(100-600 \mu \mathrm{g} / \mathrm{mL})$ for 4 hours was over $80.51 \%$. In addition, the viability of cells pretreated with SynB-PEG-GS nanoparticles for 12 hours was $78.22 \%, 70.60 \%$, and $62.70 \%$ at a nanoparticle concentration of $<400 \mu \mathrm{g} / \mathrm{mL}$, $500 \mu \mathrm{g} / \mathrm{mL}$, and $600 \mu \mathrm{g} / \mathrm{mL}$, respectively. Viability of cells pretreated with PEG-GS nanoparticles $(100-600 \mu \mathrm{g} / \mathrm{mL})$ for 4 hours was $79.44 \%$. Even in brain capillary endothelial cells incubated for 12 hours with PEG-GS nanoparticles $(600 \mu \mathrm{g} / \mathrm{mL})$, viability was still $70.00 \%$. There was no significant difference
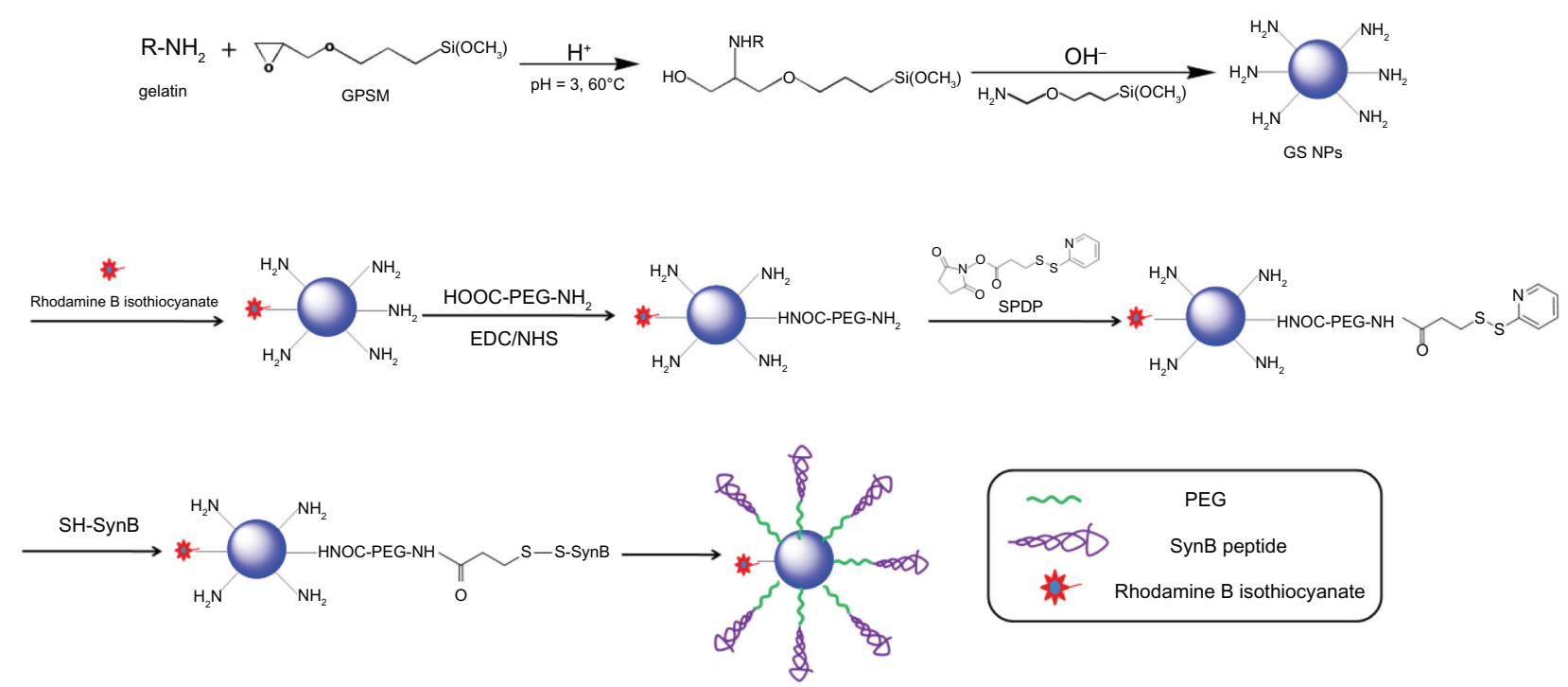

Figure I Synthesis of gelatin-siloxane nanoparticles coated with PEG and SynB peptide. 

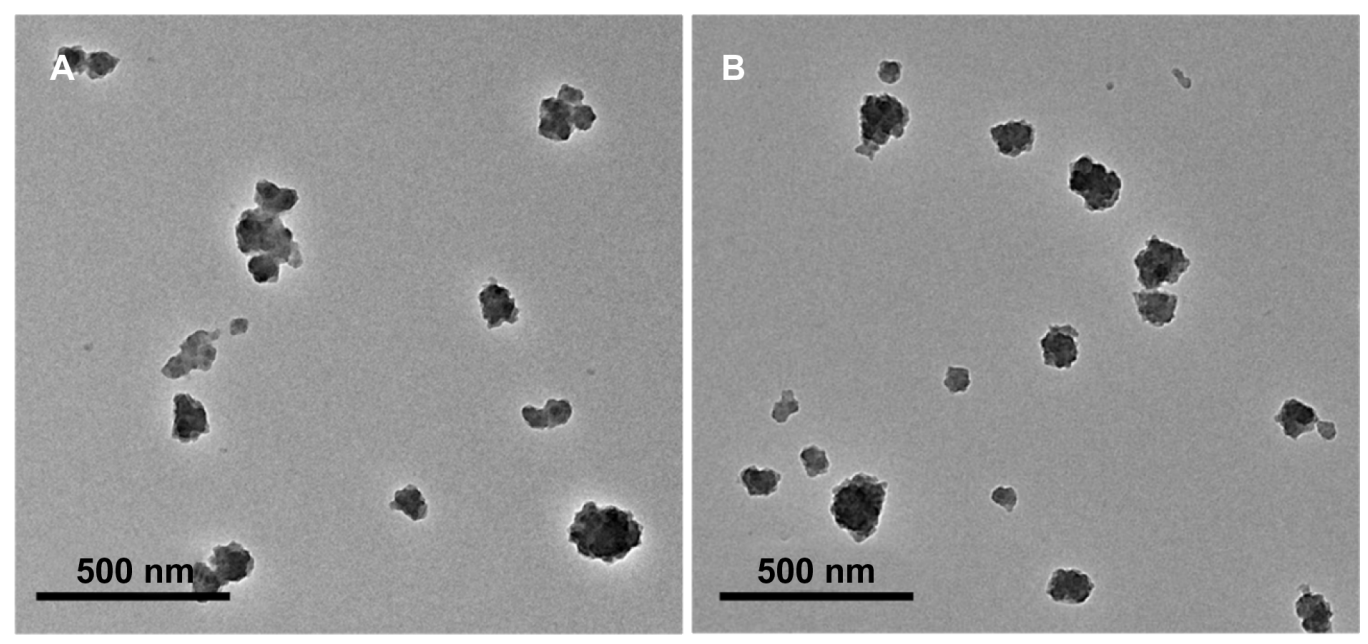

Figure 2 Transmission electron microscopic images of (A) SynB-PEG nanoparticles decorated with gelatin-siloxane, and (B) PEG-gelatin-siloxane nanoparticles.

in the toxicity of the different formulations at the same concentrations $(P>0.05)$ at any incubation time.

\section{Uptake of nanoparticles by brain capillary endothelial cells}

Figure 5 shows significant uptake of SynB-PEG-GS nanoparticles by brain capillary endothelial cells, as compared with PEG-GS nanoparticles which showed relatively poor uptake. Cells treated with PEG-GS nanoparticles were demonstrated to have negligible uptake, while those treated with SynB-PEG-GS nanoparticles showed substantial uptake. In addition, after a 4-hour incubation period, the cellular uptake index of SynB-PEG-GS nanoparticles was 1.29-fold higher than that of PEG-GS nanoparticles, and this difference was statistically significant $(P<0.05)$.

\section{Cell monolayer permeation studies}

A cocultured blood-brain barrier model confirmed by claudin-5 immunostaining was used to study the delivery of various nanoparticles to the brain in vitro. The results of SynB-PEG-GS and PEG-GS nanoparticle transport studies

Table I Physical characterization of various types of nanoparticles $(n=22)$

\begin{tabular}{lllr}
\hline Formulation & $\begin{array}{l}\text { Particle size } \\
(\mathbf{n m})\end{array}$ & \multicolumn{1}{l}{$\begin{array}{l}\text { Zeta potential } \\
(\mathbf{m V})\end{array}$} \\
\cline { 2 - 3 } & $\mathbf{D L S}$ & TEM & \\
\hline GS NPs & $180.73 \pm 11.57$ & $174.73 \pm 11.75$ & $28.50 \pm 3.33$ \\
PEG-GS NPs & $182.91 \pm 10.30$ & $174.05 \pm 11.36$ & $2.50 \pm 1.97$ \\
SynB-PEG-GS NPs & $194.55 \pm 6.43$ & $186.00 \pm 8.04$ & $31.82 \pm 3.11$ \\
\hline
\end{tabular}

Abbreviations: DLS, dynamic light scattering; GS, gelatin-siloxane; SynB-PEG-GS, SynB-PEG nanoparticles decorated with gelatin-siloxane; PEG-GS, PEG-gelatinsiloxane nanoparticles; NPs, nanoparticles; TEM, transmission electron microscopy. are shown in Figure 6. The amount of nanoparticles crossing the cocultured blood-brain barrier model showed a timedependent pattern. Moreover, the passage of SynB-PEG-GS nanoparticles across the blood-brain barrier was significantly greater than that of PEG-GS nanoparticles at the different time points $(P<0.05)$. After an 80 -minute incubation period, the quantity of SynB-PEG-GS nanoparticles that permeated across the blood-brain barrier was 1.99-fold higher than that of PEG-GS nanoparticles.

\section{Animal experiments}

In order to demonstrate delivery of the SynB-PEG-GS nanoparticles to the mouse brain, a series of in vivo fluorescence imaging system experiments was performed. Figure 7 shows the real-time in vivo biodistribution and excretion profile for SynB-PEG-GS nanoparticles in a living mouse. For the entire duration of the experiment, strong fluorescence signals were observed in the brains of mice treated with SynB-PEG-GS nanoparticles. In the first 30 minutes, there was no definite fluorescence signal from nanoparticles in the brain. The fluorescence signal in the brain area was enhanced one hour following injection and reached its highest levels 2 hours after treatment, and had receded by 4 hours after injection. However, there was no obvious fluorescence signal in the brain areas of mice treated with PEG-GS nanoparticles.

Quantitative analysis of rhodamine B isothiocyanatelabeled nanoparticle biodistribution following intravenous administration to the tail is shown in Figure 8. As indicated in Figure 8A, the total fluorescent signals excited by SynBPEG-GS and PEG-GS nanoparticles both reached a maximal level in the brain 2 hours after injection. At 24 hours after 

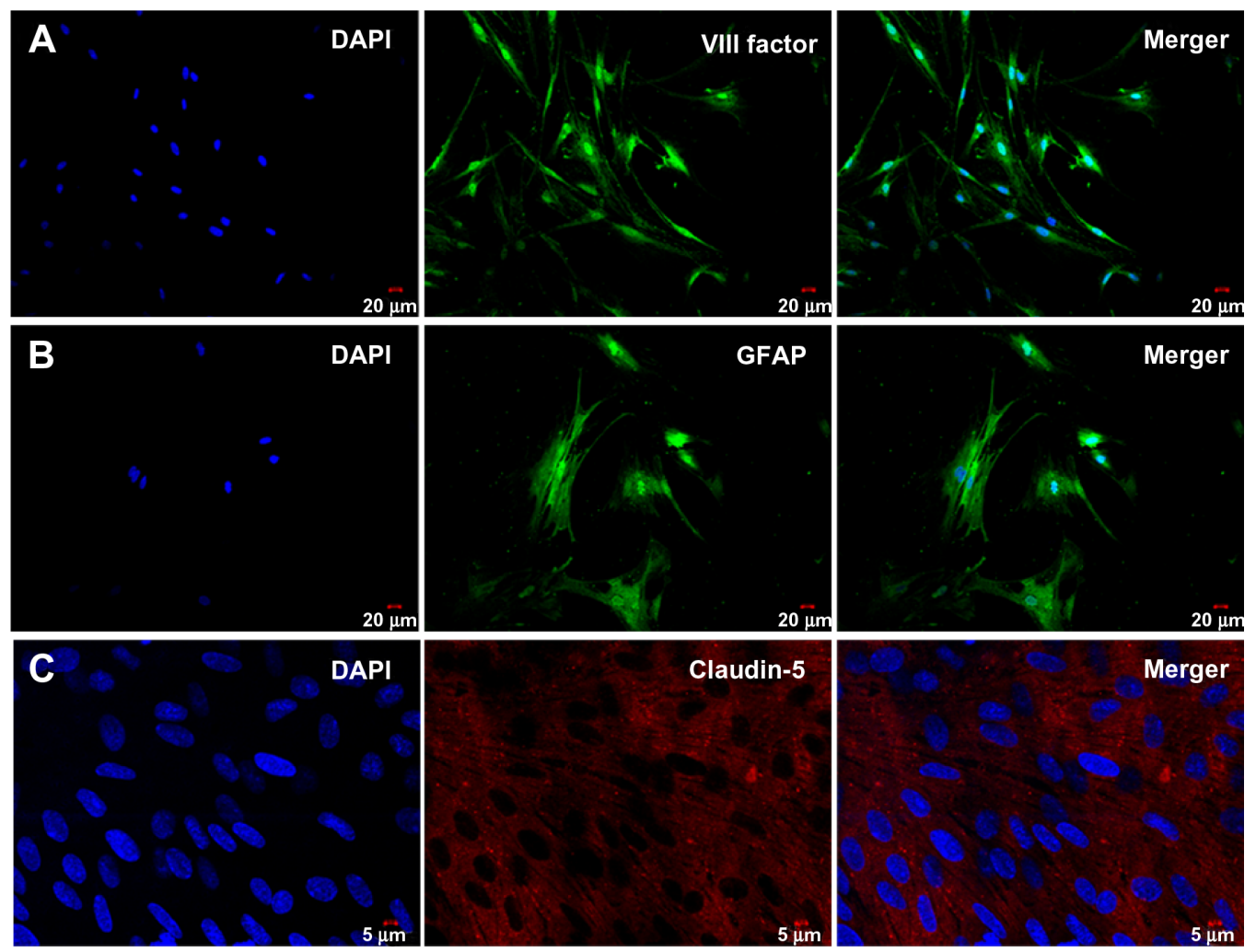

Figure 3 Characterization of cells and blood-brain barrier model by immunofluorescent staining.

injection, the fluorescent signals had faded. In addition, SynB-PEG-GS nanoparticles were present in significantly higher numbers than were PEG-GS nanoparticles at all time points $(P<0.01)$. In contrast with brain localization, the total fluorescent signals of various nanoparticles in the liver reached a maximal level at 4 hours after injection and PEG-GS nanoparticle levels were significantly higher than those of SynB-PEG-GS nanoparticles $(P<0.01)$ at the different time points, as shown in Figure 8B.

\section{Discussion}

In this study, a novel nanoparticle for drug delivery to the brain was synthesized by decorating SynB-PEG with gelatinsiloxane. The basic properties of nanoparticles, such as diameter and zeta potential, play an important role for longevity in the blood and for crossing the blood-brain barrier. Generally, the size of nanoparticles for delivery to the brain needs to be under $200 \mathrm{~nm}$ to enable endocytosis by brain capillary cells. Our study demonstrates that both SynB-PEG-GS and PEG-GS nanoparticles had a spherical shape and a mean diameter of 150-200 nm (Figure 2). Therefore, modification of the SynB peptide did not affect the shape of the PEG-GS nanoparticles. As shown in Table 1, all of the nanoparticles had an average diameter of $170-190 \mathrm{~nm}$. However, the mean diameter of the nanoparticles detected by dynamic light scattering analysis was higher than that detected by transmission electron microscopy, which might be due to hydration of the PEG associated with the nanoparticles. ${ }^{24}$ The modification of gelatin-siloxane nanoparticles with PEG could result in a decrease in the zeta potential to a nearly neutral level $(2.50 \pm 1.97 \mathrm{mV})$. With further attachment of the positively charged SynB peptide, the zeta potential value increased to $31.82 \pm 3.11 \mathrm{mV}$, which makes it possible to deliver plasmid

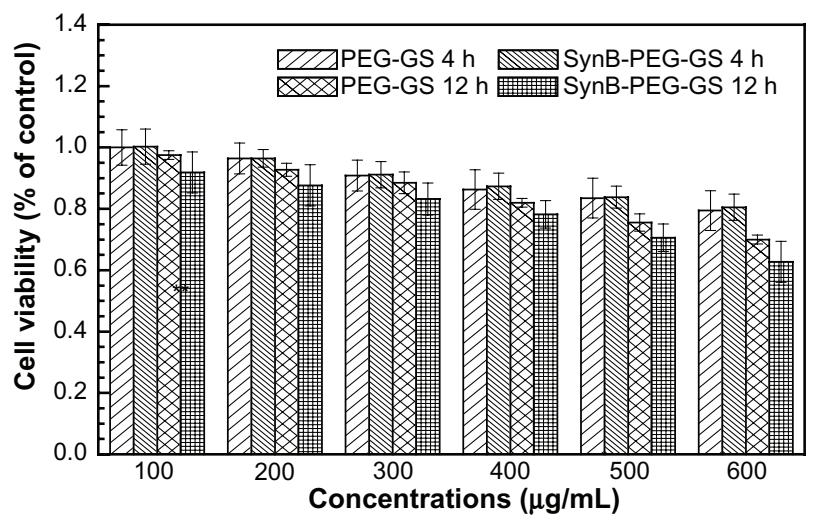

Figure 4 Brain capillary endothelial cell viability detected by MTT assay. Abbreviations: SynB-PEG-GS, SynB-PEG nanoparticles decorated with gelatinsiloxane; PEG-GS, PEG-gelatin-siloxane nanoparticles. 


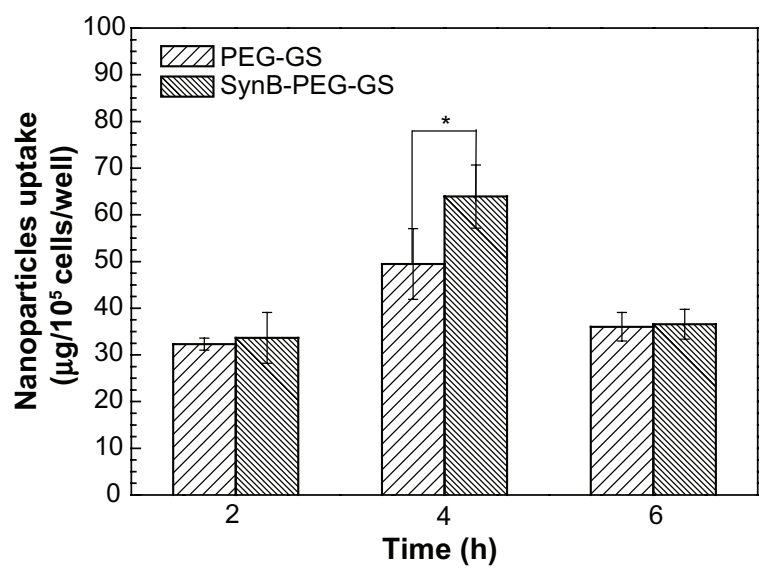

Figure 5 Amounts of SynB-PEG-GS and PEG-GS taken up by brain capillary endothelial cells detected by inductively coupled plasma mass spectrometry.

Notes: $P<0.05$ indicates a statistically significant difference; means \pm standard deviations are indicated $(n=4)$.

Abbreviations: SynB-PEG-GS, SynB-PEG nanoparticles decorated with gelatinsiloxane; PEG-GS, PEG-gelatin-siloxane nanoparticles.

DNA to the brain without compromising the blood-brain barrier. ${ }^{25}$ These cationic nanoparticles are thus likely to bind to the anionic luminal plasma membrane, and subsequently become internalized into cells via endocytosis. ${ }^{26}$

The ability of these nanoparticles to cross the blood-brain barrier was investigated using an in vitro cocultured model consisting of primary rat brain capillary endothelial cells and astrocytes. In our study, brain capillary endothelial cells and astrocytes were isolated from 3-week-old Sprague-Dawley rats. To determine whether these cells were brain capillary endothelial cells or astrocytes, respectively, we measured endothelial cell factor VIII and glial fibrillary acidic protein by immunofluorescence. As shown in Figure 3, the brain

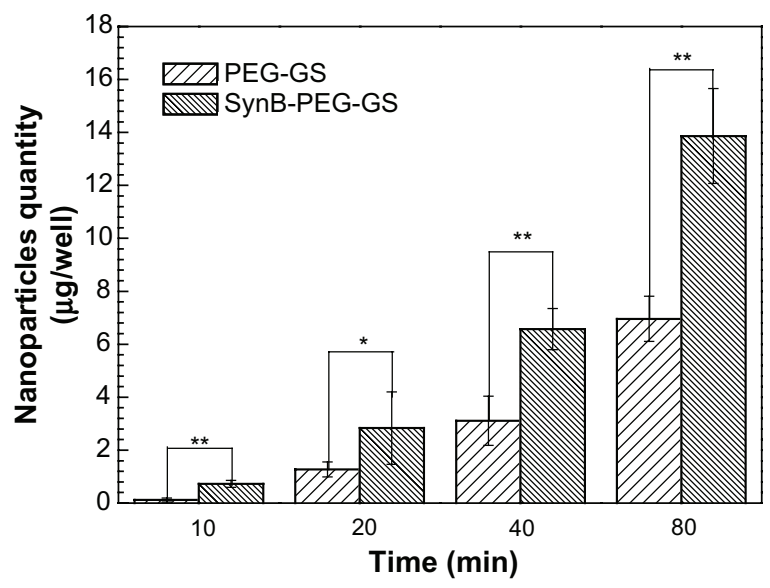

Figure 6 Amount of nanoparticles transported across the cocultured blood-brain barrier model detected by inductively coupled plasma mass spectrometry.

Notes: $* * P<0.01$ and $* P<0.05$ indicate a statistically significant difference; means \pm standard deviations are shown $(n=5)$.

Abbreviations: SynB-PEG-GS, SynB-PEG nanoparticles decorated with gelatinsiloxane; PEG-GS, PEG-gelatin-siloxane nanoparticles.

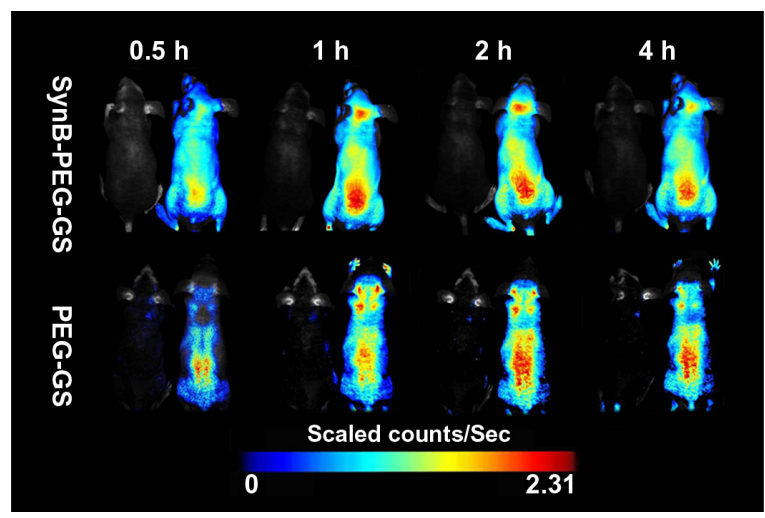

Figure 7 Dynamic imaging of nude mice administered rhodamine B isothiocyanatelabeled nanoparticles. Mice without injection were located in the left for each group. Abbreviations: SynB-PEG-GS, SynB-PEG nanoparticles decorated with gelatinsiloxane; PEG-GS, PEG-gelatin-siloxane nanoparticles.

capillary endothelial cells showed elongated, fusiform morphology and positive immunostaining for factor VIII (Figure 3A). The astrocytes characterized were polygonal and showed positive immunostaining for glial fibrillary acidic protein (Figure 3B). Claudin-5 immunofluorescence was performed for the blood-brain barrier model of cocultured brain capillary endothelial cells and astrocytes, as shown in Figure $3 \mathrm{C}$. In the blood-brain barrier model, the tight junction protein, claudin-5, was strongly expressed in the vicinity of cell borders, and as clear and smooth lines.

Evaluation of the toxicity of nanocomplexes on cells in culture is crucial to their eventual use in biomedical applications. We used a MTT cell viability assay to evaluate whether the prepared nanoparticles were toxic to brain capillary endothelial cells. Formazan absorbance indicated that the brain capillary endothelial cells seeded onto the different membranes were able to convert the MTT into a blue formazan product. Treatment of brain capillary endothelial cells with nanoparticles carrying the different modifications for 4 hours and 12 hours decreased cell viability in a timedependent and concentration-dependent manner (Figure 4). Viability was over $80.51 \%$ in brain capillary endothelial cells treated with SynB-PEG-GS nanoparticles $(100-600 \mu \mathrm{g} / \mathrm{mL})$ for 4 hours. Even after incubation for 12 hours, the viability of brain capillary endothelial cells was $78.22 \%, 70.60 \%$, and $62.70 \%$ at nanoparticle concentrations $<400 \mu \mathrm{g} / \mathrm{mL}$, $500 \mu \mathrm{g} / \mathrm{mL}$, and $600 \mu \mathrm{g} / \mathrm{mL}$, respectively. In addition, the viability of cells pretreated with PEG-GS nanoparticles $(100-600 \mu \mathrm{g} / \mathrm{mL})$ for 4 hours was over $79.44 \%$. Even in brain capillary endothelial cells incubated for 12 hours with PEGGS nanoparticles $(600 \mu \mathrm{g} / \mathrm{mL})$, viability was still $70.00 \%$. At the same time point of incubation, there was no significant difference in the toxicity of the different formulations at any 
A
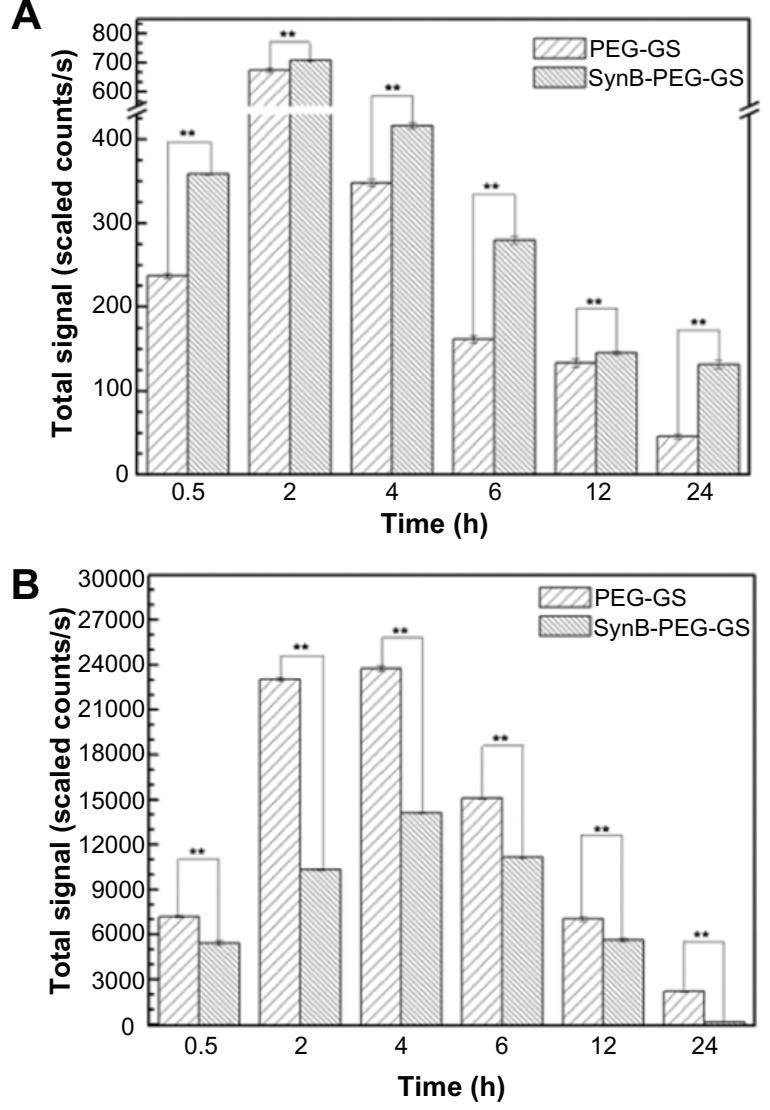

Figure 8 Brain (A) and liver (B) distribution of SynB-PEG-GS nanoparticles and PEG-GS nanoparticles, after injection into mice up to 24 hours.

Notes: ${ }^{*} P P<0.01$ indicate a statistically significant difference; means \pm standard deviations are indicated $(n=7)$.

Abbreviations: SynB-PEG-GS, SynB-PEG nanoparticles decorated with gelatinsiloxane; PEG-GS, PEG-gelatin-siloxane nanoparticles.

of the given concentrations $(P>0.05)$. These results indicate that the SynB-PEG-GS nanoparticles were nontoxic and had good biocompatibility, and there may be two reasons for this observation. First, gelatin and GPSM, the materials used in the construction of the various nanoparticles, had good compatibility, as we have previously reported. ${ }^{22}$ Second, the toxicity of the PEG component has also been reported to be acceptably low. ${ }^{27}$

To determine whether nanoparticles decorated by the SynB peptide were internalized into brain capillary endothelial cells, the cellular uptake of SynB-PEG-GS and PEG-GS nanoparticles by brain capillary endothelial cells was evaluated for the different time intervals using inductively coupled plasma mass spectrometry. As indicated in Figure 5, the cellular uptake of SynB-PEG-GS nanoparticles was higher than that of PEG-GS nanoparticles for all incubation times. In particular, the value for SynB-PEG-GS nanoparticles was 1.29-fold higher than that for PEG-GS nanoparticles after a 4-hour incubation period. To investigate this further, a cocultured blood-brain barrier model was used to test the ability of the various nanoparticles to cross the blood-brain barrier in vitro. The amount of nanoparticles which crossed in the cocultured blood-brain barrier model showed a time-dependent pattern (Figure 6). Moreover, SynB-PEG-GS nanoparticle levels were significantly higher than those of PEG-GS nanoparticles at various time points $(P<0.05)$. After an 80 -minute incubation period, the quantity of SynB-PEG-GS nanoparticles that had permeated was 1.99-fold greater than that of PEG-GS nanoparticles. The results of the in vitro study showed that PEG-GS nanoparticles decorated with SynB peptide did improve the ability of the nanoparticles to cross the blood-brain barrier. SynB peptide is from a new family of cell-penetrating peptides, an 18 amino acid peptide originally isolated from porcine leukocytes, which does not require receptors or an energy-dependent pathway to penetrate the membrane. ${ }^{28}$ As a sequence capable of crossing the plasma membrane, cell-penetrating peptides are an attractive tool for delivering nanoparticles into cells. Penetration of the plasma membrane by cell-penetrating peptides is not dependent on linkage with other molecules, and nanoparticles up to $200 \mathrm{~nm}$ in diameter can be transported across the plasma membrane by this method..$^{29}$

Finally, biodistribution studies of the rhodamine-loaded nanoparticles were performed in mice to analyze their tissue selectivity, body clearance, and potential brain localization. Various rhodamine-loaded gelatin-siloxane nanoparticles were injected via the caudal vein using a rat model, and accumulation of the different gelatin-siloxane nanoparticles was then evaluated qualitatively and quantitatively using an in vivo imaging system. Figure 7 shows dynamic imaging of the nude mice, with strong fluorescence signals observed in the brain area of the mice treated with SynB-PEG-GS nanoparticles at various time points. However, there was no obvious fluorescence signal in the brain areas of mice treated with PEG-GS nanoparticles. These results suggest that PEG-GS nanoparticles decorated with the SynB peptide have significant potential for brain targeting and delivery. Further, in order to confirm the amount of nanoparticles within brain tissue and other organs, the mice were sacrificed at $0.5,2,4,6,12$, and 24 hours after injection. Their brains and livers were collected immediately, washed twice with physiological saline solution, and then visualized using a Maestro in vivo imaging system. As shown in Figure 8, SynB-PEG-GS nanoparticle concentrations were significantly higher than those of PEG-GS nanoparticles at all time points $(P<0.01)$ in the brain area. However, unlike 
localization in the brain, total fluorescent signals of PEG-GS nanoparticles were significantly higher than those of SynBPEG-GS nanoparticles $(P<0.01)$ in the liver area at the different time points. These results indicate that the modified SynB peptide could not only help PEG-GS nanoparticles to evade the reticuloendothelial system but also to cross the blood-brain barrier.

\section{Conclusion}

Improved delivery of nanoparticles to the brain was achieved by conjugating SynB peptide with PEG and gelatin-siloxane. We have demonstrated that SynB-PEG-GS nanoparticles have a good morphology and size distribution, and favorable cytotoxic properties. Moreover, SynB-PEG-GS nanoparticles showed higher efficiency in uptake by brain capillary endothelial cells and ability to cross the blood-brain barrier. In addition, biodistribution studies of the different rhodamine-loaded nanoparticles demonstrated that the modified SynB peptide could not help PEG-GS nanoparticles to evade the reticuloendothelial system also cross the blood-brain barrier. We believe that SynB-PEG-GS nanoparticles hold great promise for efficient, noninvasive, and brain-targeting drug delivery.

\section{Acknowledgment}

This work was financially supported by the National Natural Science Foundation of China (81172394), the National Natural Science Foundation of China (30970733), the National Basic Research Program of China (2010CB732402), and the Natural Science Foundation of Fujian Province of China (2006J0188).

\section{Disclosure}

The authors report no conflicts of interest in this work.

\section{References}

1. Jain KK. Role of nanobiotechnology in the personalized management of glioblastoma multiforme. Nanomedicine (Lond). 2011;6(3):411-414.

2. Pillay V, Modi G, Choonara YE, Ndesendo VMK, du Toit LC, Naidoo D. Nanotechnological applications for the treatment of neurodegenerative disorders. Prog Neurobiol. 2009;88(4):272-285.

3. Tian XH, Lin XN, Wei F, et al. Enhanced brain targeting of temozolomide in polysorbate- 80 coated polybutylcyanoacrylate nanoparticles. Int $J$ Nanomedicine. 2011;6:445-452.

4. Kreuter J, Ulbrich K, Hekmatara T, Herbert E. Transferrin- and transferrin-receptor-antibody-modified nanoparticles enable drug delivery across the blood-brain barrier (BBB). Eur J Pharm Biopharm. 2009;71(2):251-256.

5. Kreuter J. Nanoparticles - a historical perspective. Int $J$ Pharm. 2007;331(1):1-10.
6. Kopelman R, Koo YEL, Reddy GR, et al. Brain cancer diagnosis and therapy with nanoplatforms. Adv Drug Deliv Rev. 2006;58(14): $1556-1577$.

7. Moghimi SM, Hunter AC, Murray JC. Nanomedicine: current status and future prospects. FASEB J. 2005;19(3):311-330.

8. Jiang XG, Li JW, Feng L, et al. Targeting the brain with PEG-PLGA nanoparticles modified with phage-displayed peptides. Biomaterials. 2011;32(21):4943-4950.

9. Jia XR, He H, Li Y, et al. PEGylated poly(amidoamine) dendrimerbased dual-targeting carrier for treating brain tumors. Biomaterials. 2011;32(2):478-487.

10. Huang YW, Liu BR, Chiang HJ, Lee HJ. Cell-penetrating peptidefunctionalized quantum dots for intracellular delivery. $J$ Nanosci Nanotechnol. 2010;10(12):7897-7905.

11. Jiang XG, Hu KL, Shi YB, Jiang WM, Han JY, Huang SX. Lactoferrin conjugated PEG-PLGA nanoparticles for brain delivery: Preparation, characterization and efficacy in Parkinson's disease. Int J Pharm. 2011;415(1-2):273-283.

12. Jiang C, Liu Y, Li JF, et al. A leptin derived 30-amino-acid peptide modified pegylated poly-L-lysine dendrigraft for brain targeted gene delivery. Biomaterials. 2010;31(19):5246-5257.

13. Allen TM, Hansen C. Pharmacokinetics of stealth versus conventional liposomes: effect of dose. Biochim Biophys Acta. 1991;1068(2):133-141.

14. Klibanov AL, Maruyama K, Torchilin VP, Huang L. Amphipathic polyethylene glycols effectively prolong the circulation time of liposomes. FEBS Lett. 1990;268(1):235-237.

15. Gao X, Wu B, Zhang Q, et al. Brain delivery of vasoactive intestinal peptide enhanced with the nanoparticles conjugated with wheat germ agglutinin following intranasal administration. J Control Release. 2007;121(3):156-167.

16. Lu W, Wan J, She Z, Jiang X. Brain delivery property and accelerated blood clearance of cationic albumin conjugated pegylated nanoparticle. J Control Release. 2007;118(1):38-53.

17. Lo SL, Wang S. An endosomolytic Tat peptide produced by incorporation of histidine and cysteine residues as a nonviral vector for DNA transfection. Biomaterials. 2008;29(15):2408-2414.

18. Zorko M, Langel U. Cell-penetrating peptides: mechanism and kinetics of cargo delivery. Adv Drug Deliv Rev. 2005;57(4):529-545.

19. Drin G, Cottin S, Blanc E, Rees AR, Temsamani J. Studies on the internalization mechanism of cationic cell-penetrating peptides. $J$ Biol Chem. 2003;278(33):31192-31201.

20. Rousselle C, Clair P, Smirnova M, et al. Improved brain uptake and pharmacological activity of dalargin using a peptide-vector-mediated strategy. J Pharmacol Exp Ther. 2003;306(1):371-376.

21. Adenot M, Merida P, Lahana R. Applications of a blood-brain barrier technology platform to predict CNS penetration of various chemotherapeutic agents. 2. Cationic peptide vectors for brain delivery. Chemotherapy. 2007;53(1):73-76.

22. Wang ZY, Zhao Y, Ren L, et al. Novel gelatin-siloxane nanoparticles decorated by Tat peptide as vectors for gene therapy. Nanotechnology. 2008;19(44):445103.

23. Deli MA, Nakagawa S, Kawaguchi H, et al. A new blood-brain barrier model using primary rat brain endothelial cells, pericytes and astrocytes. Neurochem Int. 2009;54(3-4):253-263.

24. Sahoo SK, Ma W, Labhasetwar V. Efficacy of transferrin-conjugated paclitaxel-loaded nanoparticles in a murine model of prostate cancer. Int J Cancer. 2004;112(2):335-340.

25. Santra S, Yang HS, Holloway PH, Stanley JT, Mericle RA. Synthesis of water-dispersible fluorescent, radio-opaque, and paramagnetic CdS: $\mathrm{Mn} / \mathrm{ZnS}$ quantum dots: A multifunctional probe for bioimaging. $J \mathrm{Am}$ Chem Soc. 2005;127(6):1656-1657.

26. Gabathuler R. Approaches to transport therapeutic drugs across the blood-brain barrier to treat brain diseases. Neurobiol Dis. 2010;37(1):48-57. 
27. Bonneaux F, Zambaux MF, Gref R, Dellacherie E, Vigneron C. Protein C-loaded monomethoxypoly (ethylene oxide)-poly(lactic acid) nanoparticles. Int J Pharm. 2001;212(1):1-9.

28. Suzuki T, Futaki S, Niwa M, Tanaka S, Ueda K, Sugiura Y. Possible existence of common internalization mechanisms among arginine-rich peptides. J Biol Chem. 2002;277(4):2437-2443.
29. Fonseca SB, Pereira MP, Kelley SO. Recent advances in the use of cell-penetrating peptides for medical and biological applications. $A d v$ Drug Deliv Rev. 2009;61(11):953-964.

International Journal of Nanomedicine

\section{Publish your work in this journal}

The International Journal of Nanomedicine is an international, peerreviewed journal focusing on the application of nanotechnology in diagnostics, therapeutics, and drug delivery systems throughout the biomedical field. This journal is indexed on PubMed Central, MedLine, CAS, SciSearch $®$, Current Contents ${ } /$ Clinical Medicine,
Journal Citation Reports/Science Edition, EMBase, Scopus and the Elsevier Bibliographic databases. The manuscript management system is completely online and includes a very quick and fair peer-review system, which is all easy to use. Visit http://www.dovepress.com/ testimonials.php to read real quotes from published authors.

Submit your manuscript here: http://www.dovepress.com/international-journal-of-nanomedicine-journal 